\title{
The leverage effect puzzle: the case of European sovereign credit default swap market
}

\author{
Agata Kliber ${ }^{1}$
}

Published online: 17 March 2016

(C) The Author(s) 2016. This article is published with open access at Springerlink.com

\begin{abstract}
One of the stylized facts about the behaviour of time series is that their volatility exhibits asymmetrical responses to good and bad news. In the case of stock markets, volatility seems to rise when the stock price decreases and fall when the stock price increases. This so-called "leverage effect" was first described by Black (Proceedings of the 1976 meeting of the business and economic statistics section, pp 177-181, 1976). The concept is not new and has already been comprehensively studied and implemented in many volatility models (GARCH and SV) in the form of an additional parameter in the volatility equation. However, there is no study or a theoretical explanation of the leverage effect in sovereign credit default swap spreads (hereinafter: sCDS). In this article, we discuss the possible behaviour of sCDS volatility and explain it by way of reference to the Prospect Theory by Kahneman and Tversky (Econometrica 47(2):263-292, 1979). We estimate a series of stochastic volatility models with the leverage effect, proposed by Yu (J Econom 127(2):165-178, 2005). In this model, the "leverage effect" is, in fact, the same as a coefficient of the correlation between the current return of an asset and its expected future volatility. We show that the effect does exist and differs across markets. As far as the safe European markets are concerned, the parameter is negative; in the case of extremely risky economies-it is positive. In markets of medium risk the effect varies depending on the relationship between the perceived risk and the value of the sCDS premium.
\end{abstract}

Keywords Credit default swap · Emerging markets · Leverage effect . Stochastic volatility

JEL classification G15 · F37

\footnotetext{
Agata Kliber

agata.kliber@ue.poznan.pl

1 Poznań University of Economics, Al. Niepodległości 10, 61-875 Poznan, Poland
} 


\section{Introduction}

Credit default swaps (hereinafter: CDS) are financial instruments that allow the buyer to protect himself or herself against the risk of the default of his debtor. Sovereign credit default swaps are a special kind of CDS. In this case, the debtor is the country the bond of which the investor owns (to be precise: the obligation to possess the bond was imposed in November 2012, but only in the European market-see e.g. ISDA 2014). The spread (price or premium-i.e. the amount of quarterly payment from the protection buyer to the protection seller denoted in basis points) of sCDS instruments is associated with the solvency risk of the country. It can be interpreted as a forward-looking measure of idiosyncratic sovereign credit risk and as such it monitors investors' assessment that a given country might suffer a financial crisis (Calice et al. 2015).

CDS contracts are sometimes compared to insurance. The buyer of the CDS pays a pre-specified quarterly premium to the CDS seller (or: writer) for protection against a credit event, i.e. the situation when the reference entity is not able to pay its obligations. There are various types of credit events. In the case of the European instruments, three kinds of them can be distinguished. A "failure to pay" is triggered by a payment default by the reference entity, in the amount of at least USD 1 million, on certain debt obligations after the expiration of any grace period. A "restructuring" credit event is triggered by one of five specified events impacting on the reference entity's obligations, in relation to the amount of at least USD 10 million, and only provided that it results from deterioration in the creditworthiness or the financial condition of the reference entity. These events are: reduction in interests payable, reduction in principal or premium payable, a postponement or deferral of certain payment or accrual dates, a change in ranking or priority resulting in "subordination", a change in the payment currency to any currency that does not qualify as a "permitted currency". The last one is a "repudiation/moratorium" credit event, applying only to the sovereign CDS and triggered either when the sovereign entity repudiates/declares moratorium in relation to the amount of at least USD 10 million, or when a "failure to pay"/"restructuring" occurs within 60 days after the initial repudiation or moratorium (see also Grady and Lee 2012, or Kliber 2013).

Most of the studies dealing with the CDS market concentrate on the investigation of factors influencing the dynamics of the spreads. Calice et al. (2015) showed that it is possible to decompose the sCDS spread into two components: the stationary and non-stationary one, where one of the components responds to the shocks to the underlying bond market, while the other responds to the shocks specific to the sCDS market. According to most researchers, sCDS premium is mostly influenced by global variables, unrelated to the economic situation of the country (Longstaff et al. 2011; Ang and Longstaff 2013; Adam 2013; Augustin 2014 and many others). However, during crisis periods, domestic factors grew in importance (see for instance: Arghyrou and Kontonikas 2012; Carlos et al. 2010).

More and more authors stress the fact that the dynamics of CDS spreads are strongly affected also by their liquidity. Meine et al. (2015) as well as Lesplingart et al. (2012), who studied corporate CDS, conclude that the liquidity effect is as strong as the fundamental determinants of default risk, and that this effect is intensified during the 
subprime crisis. The influence of liquidity on the dynamics of the sovereign CDS was confirmed by, among others, Adam (2013) or Heinz and Sun (2014), who claimed that in a crisis period less liquid markets tend to be penalized and suffer from a larger increase in their sCDS spreads.

In this paper, we also address the problem of assessing the dynamics of the SCDS. Unlike most scholars, we do not aim at determining the external factors influencing the spread, but we try to find out whether the volatility of the spread reacts in the same way to the growth of the spread change as it does to its decline. This asymmetric reaction of volatility was first described by Black (1976) in the dynamics of the stocks. Such "leverage" was originally associated with the financial leverage of a given company, but recently more and more studies have found its existence even in the case of companies that use no financial leverage at all. The phenomenon has been implemented in many volatility models (asymmetric GARCH and SV models). It is incorporated into models as an additional parameter in the volatility equation (e.g. Glosten et al. 1993) or as a correlation between return and volatility (e.g. Shephard 1996 or Yu 2005), which is estimated. Its sign_-positive or negative-signals whether asymmetry is present in the data.

Although the "leverage effect" has already been widely studied and many theories explaining it have been developed, to the best of our knowledge there is no paper exploring the asymmetric behaviour of the CDS volatility. ${ }^{1}$ Due to the nature of sCDS, a "financial" explanation of the phenomenon is impossible, but we can explain it via the behaviour of market participants. Therefore, we present a simple model of the possible common behaviour of volatility and returns, based upon the Prospect Theory, and we formulate hypotheses of the possible interrelations between returns and volatility. Eventually, we test the hypotheses estimating volatility of several European sCDS spreads (daily data from the period 2008-2013) with the use of the SV model with the so called "leverage effect" (Meyer and Yu 2000; Yu 2005). In our approach, the "leverage effect" is associated with the correlation between volatility and return of the instrument. In doing so, we have obtained negative, positive and insignificant values of the parameter, depending on the country being investigated.

The remainder of the paper has the following content. First, we introduce the concept of the leverage effect in the time-series data. Next, in an attempt to address the characteristics of the sCDS market and types of investors and investment strategies, as well as referring to the Prospect Theory of Kahneman and Tversky (1979), we present the theoretical explanation of possible leverage parameter values. Subsequently, we describe the model used to explore the leverage effect (Yu 2005). In the empirical part, we focus on the dynamics of the sovereign CDS prices (with the source of data being Reuters DataStream) over the period of 2008-2013 and descriptive statistics. Finally, we present the results of the study and develop a ranking of countries based upon the leverage effect.

\footnotetext{
1 There are some papers dealing with CDS contracts and financial leverage, but they usually address this issue on the corporate level. A case in point is the work by Saretto and Tookes (2013), where the authors investigate the impact of hedging risk through CDS on the company's capital structure.
} 


\section{Leverage effect: an overview of the literature}

The leverage effect in financial asset prices was first described by Black (1976). The author addressed the characteristic behaviour of the volatility of financial time series that reacted asymmetrically to good and bad news. It has been observed that volatility seems to rise as the stock price decreases, and it declines when the stock price increases. This effect was typically attributed to the so-called financial leverage. If a company issues stocks and bonds, its debt-to-equity ratio changes when the stock price changes (ceteris paribus). When the stock price goes up, the equity value increases more substantially than the debt value, and the debt-to-equity ratio decreases. Thus, the risk affecting the company decreases, and so does volatility. When stock prices fall, the equity value decreases more substantially than the debt value, and the risk and volatility associated with the company increase (see also Figlewski and Wang 2000).

However, more and more researchers challenge this financial explanation. For instance, Aydemir et al. (2007) show that when interest rates and the price of risk are kept constant, the financial leverage generates little variation in stock return volatility at the market level but significant volatility at the level of a single company. If interest rates and the price of risk are time-varying, the financial leverage also has little effect on the dynamics of stock return volatility at the market level in the case of all companies, except for small ones.

Figlewski and Wang (2000) confirm the existence of the leverage effect for falling stock prices, but a very weak or no leverage effect for positive returns. Thus, they suggest putting this effect to the "down-market" category. Glosten et al. (1993) showed that the results change when we switch to monthly data frequency. In this case, the unexpected return has negative impact on volatility.

Hens and Steude (2009) used an experimental stock market to show that the leverage effect exists in financial markets, but its origin should not be associated with the financial leverage of a company. Namely, they demonstrate the existence of the effect even if the underlying asset does not exhibit any financial leverage at all. Similar results are presented by Hasanhodzic and Lo (2011). The authors analyze a sample of all-equity-financed companies from January 1972 to December 2008, finding that even if they do not use a financial leverage, the leverage effect is present in the data. They suggest several possible explanations of this phenomenon, ${ }^{2}$ inter alia the behavioural one (supported, among others, by Hibbert et al. 2008). Since in the case of sCDS the "financial" explanation of the leverage is impossible, we will utilize the behavioural Prospect Theory of Kahneman and Tversky (1979) to explain the possible correlation sign between volatility and returns in the case of sCDS contracts (see Sect. 4.1).

\section{CDS market participants and usage of the instruments}

The entities that are the main investors in CDS markets are banks, insurance companies, pension funds, hedge funds and other asset managers (Zhang 2013). The sCDS

\footnotetext{
2 For instance: the time-varying expected return hypothesis (Pindyck 1984; French et al. 1987; Campbell and Hentschel 1992; Chen and Ghysels 2011) or volatility-feedback (Danielsson et al. 2010).
} 
are used by investors for three major purposes: to manage (hedge) the risk associated with sovereign debt, to speculate on CDS changes, and to construct arbitrage strategies. An investor can buy protection in the form of CDS to hedge the risk of defaulting on a bond or other debt instrument. In this way, a CDS is similar to credit insurance.

The entities that use CDS for speculation are most often hedge funds. As the creditworthiness of a country deteriorates, the SCDS spread grows. If an investor decides that the creditworthiness of that country is better than the one implied by sCDS, he or she can sell the protection and earn a quarterly premium for the pre-specified period. If, on the other hand, the investor decides that the creditworthiness of the country is worse than the one implied by the sCDS spread, he or she can buy the instrument, pay a relatively small quarterly premium and make an extra profit when a credit event occurs. Instead of holding the contract, a speculator can also trade it, i.e., buy it for a short time, withdraw from the contract by selling it to another investor, enter into another contract with another entity, etc. A detailed model of speculation with CDS and its impact on the cost of the debt for the borrower is given, i.e., in Che and Sethi (2015).

Unfortunately, there is no detailed information about sCDS traders. Are sovereign creditors and insurers the dominant players, or is it rather the speculative and arbitrage traders that dominate in the market? Moreover, we know little about their strategies, that is whether they trade the contracts, or simply hold SCDS as a kind of protection. Therefore, it is unclear what kind of empirical behaviour and relationship between the price level and volatility we should expect. It should depend on the strategy of investors and their beliefs about the future risk.

\section{Leverage in the sCDS market: hypotheses based upon the Prospect Theory}

To explain possible investors' behaviour we will refer to the Prospect Theory of Kahneman and Tversky $(1979,1992)$. According to the authors, decision-making under conditions of risk can be viewed as a choice between prospects (games). A prospect $\left(x_{1}, p_{1} ; \ldots ; x_{n}, p_{n}\right)$ is a contract that produces outcome $x_{i}$ with a probability $p_{i}\left(p_{1}+\ldots+p_{n}=1\right)$. The value of the prospect can be expressed in terms of two scales: $\pi$ and $v$. The first scale associates a decision weight $\pi(p)$ with each probability $p$.The decision weight reflects the impact of $p$ on the overall value of prospects. The second weight assigns to each outcome $x$ a number $v(x)$, which reflects the subjective value of that outcome. The outcomes are defined relative to a reference point (zero point in the value scale). The scale $v$ is interpreted as the measure of the value of deviations from the reference point-i.e. gains and losses (Kahneman and Tversky 1979).

What is important for our model is that the decision function is relatively shallow in an open interval, but changes abruptly near the end-points. As a result, people can either overweight or neglect highly unlikely events, as well as exaggerate or neglect the difference between certainty and a high probability. People tend to be risk-averse when their possible gains have high (or moderate) probabilities, or when likely losses have small probabilities. People become risk seekers when losses have moderate probabilities, or when gains have small probabilities (see: Table 1). Thus, the value function for gains is concave, while it is convex for losses. 
Table 1 Risk aversion and risk seeking, depending on the probability of losses and gains

\begin{tabular}{|c|c|c|}
\hline & Gains & Loses \\
\hline \multirow[t]{2}{*}{ High probability } & Risk aversion: & Risk seeking: \\
\hline & $\begin{array}{l}\text { People tend to be risk-averse when their } \\
\text { possible gains have high (or moderate) } \\
\text { probabilities e.g. } \\
\pi(0.8) v(4000)<v(3000) \text {. }\end{array}$ & $\begin{array}{l}\text { People are risk-seeking when their } \\
\text { possible losses have moderate } \\
\text { probabilities, e.g. } \\
\pi(0.8) v(-4000)>v(-3000) \text {. }\end{array}$ \\
\hline \multirow[t]{2}{*}{ Low probability } & Risk seeking: & Risk aversion: \\
\hline & $\begin{array}{l}\text { People are risk-seeking when their } \\
\text { possible gains have small probabilities, } \\
\text { e.g. } \pi(0.001) v(5000)>v(5)\end{array}$ & $\begin{array}{l}\text { People tend to be risk-averse when their } \\
\text { possible high losses have small } \\
\text { probabilities, e.g. } \\
\pi(0.001) v(-5000)<v(-5) \text {. }\end{array}$ \\
\hline
\end{tabular}

Based upon: (Kahneman 2011)

\subsection{A simple model of investors' behaviour in the sCDS market}

Since the probabilities of default based on spreads are usually low (see: Table 2), we postulate that the Prospect Theory could be useful to model hypothetical behaviour of market participants. Although the Prospect Theory is usually used to describe the behaviour of individual investors, there are works demonstrating that it can be applicable also to the institutional ones (see for instance: Olsen 1997).

To make our model simple, we make the following assumptions:

- The process of making a decision whether to enter into the contract is determined by the implied probability of default (based on the spread value), investors' opinion about the credibility of the country, and the value of the spread.

- A transaction can be made when the demand of protection-seekers (and/or speculators who would buy the contract) meets the supply of the speculators selling sCDS.

- Excess volatility is generated through extensive trade (see for instance: Lamoureux and Lastrapes 1990; Kalev et al. 2004; Będowska-Sójka 2014 and many others).

The sCDS premium reflects the probability of credit event. It can be decomposed into the probability of default (PD) and expected loss (EL) (ECB 2009):

$$
p=E L+P D
$$

Thus, the growth of the premium can be caused either by the increase in the expected loss, or by the increase in the default probability. We can write the dependence between the probability of default and the value of the spread in the following way (ECB 2009):

$$
p=P D(1-R R)
$$

where PD is the probability of default and RR - the recovery rate. Some authors suggest that the probability of default and loss given default (which is equal to $1-R R$ ) may be cyclically interdependent, i.e. there is a negative correlation between the default 
Table 2 Descriptive statistics of the changes of 5-year sCDS of selected European economies during the period: October 2008-October 2013

\begin{tabular}{|c|c|c|c|c|c|c|c|c|c|}
\hline & Variable & Obs. no & Missing & Minimum & Mean & Maximum & SD & Skewness & $\begin{array}{l}\text { Probability of } \\
\text { default (in \%) - } \\
\text { an average }\end{array}$ \\
\hline 1 & Germany (D) & 1316 & 0 & -13.89 & -0.01 & 19.01 & 2.13 & -0.14 & 0.553 \\
\hline 2 & UK (D) & 12952 & 21 & -18.89 & -0.02 & 19.12 & 2.87 & 0.17 & 1.046 \\
\hline 3 & Sweden (D) & 1316 & 0 & -27 & 0.01 & 64 & 3.16 & 0.12 & 0.683 \\
\hline 4 & France (D) & 1316 & 0 & -29.5 & 0 & 25.48 & 4.05 & -0.09 & 1.073 \\
\hline 5 & Austria (D) & 1316 & 0 & -31.28 & 0.01 & 124 & 5.34 & 0.64 & 1.043 \\
\hline 6 & Czech & 1316 & 0 & -60 & -0.01 & 55 & 6.25 & 0.41 & 1.68 \\
\hline 7 & Slovakia & 1316 & 0 & -45 & 0.01 & 55 & 6.39 & 0.54 & 2.026 \\
\hline 8 & Slovenia & 1316 & 0 & -45.06 & 0.18 & 60 & 6.89 & 1.35 & 2.99 \\
\hline 9 & Poland & 1316 & 0 & -83.9 & -0.04 & 63.9 & 8.12 & -0.81 & 2.509 \\
\hline 10 & Spain (D) & 1316 & 0 & -75.24 & 0.06 & 61.31 & 10.55 & -0.2 & 3.342 \\
\hline 11 & Italy (D) & 1316 & 0 & -79.99 & 0.08 & 89.37 & 10.84 & -0.31 & 3.3 \\
\hline 12 & Estonia & 1316 & 0 & -110 & -0.18 & 160 & 11.53 & 1.3 & 2.825 \\
\hline 13 & Iceland (D) & 1316 & 0 & -100 & -0.57 & 200 & 11.66 & 1.69 & 6.366 \\
\hline 14 & Bulgaria & 1316 & 0 & -109.85 & -0.14 & 104.75 & 11.88 & 0.67 & 4.221 \\
\hline 15 & Turkey & 1316 & 0 & -120 & -0.15 & 140 & 12.54 & 0.45 & 3.452 \\
\hline 16 & Hungary & 1316 & 0 & -85 & 0.06 & 129.45 & 13.68 & 2.04 & 5.608 \\
\hline 17 & Lithuania & 1316 & 0 & -137.5 & -0.13 & 157.5 & 13.91 & 0.97 & 4.586 \\
\hline 18 & Romania & 1316 & 0 & -143.7 & -0.13 & 173.2 & 14.35 & 1.06 & 5.211 \\
\hline 19 & Ireland (D) & 1316 & 0 & -137.21 & 0.02 & 101.18 & 14.6 & 0 & 5.52 \\
\hline 20 & Latvia & 1316 & 0 & -170 & -0.21 & 168.85 & 19.8 & 0.39 & 5.89 \\
\hline 21 & Russia & 1316 & 1 & -196 & -0.15 & 285 & 20.52 & 1.61 & 3.83 \\
\hline 22 & Portugal (D) & 1316 & 0 & -199.91 & 0.2 & 187.6 & 24.02 & -1.11 & 7.346 \\
\hline 23 & Ukraine & 1316 & 1 & -800 & -0.1 & 1594.6 & 68.89 & 0.9 & 17.227 \\
\hline 24 & Greece (D) & 1316 & 0 & -1669.3 & 11.27 & 4943.9 & 239.45 & -0.34 & 98.845 \\
\hline
\end{tabular}

Data is sorted by standard deviation. Probability of default is computed assuming $40 \%$ recovery rate

rate and the recovery rate over the cycle (ECB 2009). This would imply a positive correlation between loss given default and the probability of default.

CDS-implied probabilities are risk neutral, and especially in the case of advanced economies, they are usually higher than physical or real world default probabilities (as reflected, e.g., in credit ratings). The growth of sCDS spreads may also reflect expectations of slower economic growth and the need to finance large budget deficits in an economic downturn. Therefore, sovereign CDSs may also capture the migration risk of moving to a lower credit rating (ECB 2009).

Let us denote the expected value of the premium payment from the protection buyer by $X$ and the expected value of the payment from the protection seller in the case of default by $Y$. The seller can sell the contract and then he may lose $Y$ with probability $P D=p /(1-R R)$, or-if he does enter into the contract-he loses the quarterly payments $X$ (let us denote them by $\sum p \cdot N$, where $N$ is the con- 
tract value) with probability 1 (for the sake of simplicity we omit the discounting factor). Thus, the investor has to choose between the two contracts of the following values: $\pi(P D) v(-Y) \approx \pi\left(\frac{p}{1-R R}\right) v(-N(1-R R))$ and: $v(-X) \approx v\left(\sum p \cdot N\right)$. The contract seller will be willing to sell the contract provided that $v\left(-\sum p \cdot N\right)<$ $\pi\left(\frac{p}{1-R R}\right) v(-N(1-R R))$, i.e. when he feels that potential loss can be compensated for by the premium payment, or when he perceives the probability of default as being unrealistic (too high).

From the point of view of the protection buyer, the situation is opposite. The buyer can choose not to enter into the contract and lose $Y$ if the credit event occurs. The probability of a credit event is obviously: $\left(1-\frac{p}{1-R R}\right)$. On the other hand, if the buyer enters into the contract, he "loses" the value of the quarterly payments with probability 1 . Thus, the value of the first contract for the protection buyers is: $v(-Y) \approx v\left(-\sum p \cdot N\right)$, while the value of the second one: $\pi\left(1-\frac{p}{1-R R}\right) v(-X) \approx$ $\pi\left(1-\frac{p}{1-R R}\right) v(-N(1-R R))$. The protection buyer will be willing to enter into the contract provided that $v\left(-\sum p \cdot N\right)>-\pi\left(1-\frac{p}{1-R R}\right) v(-N(1-R R))$, i.e. when he or she decides that the value of the premium is small enough, or that the probability of default is high enough. This is especially important, since during market downturns CDS spreads may increase disproportionately more than the probability of default owing to the fact that increasing the loss given default multiplies the initial increase (see Eqs. 1-2 and ECB 2009).

\subsubsection{Case 1: Probability of default is very low}

When the probability of default is very low, we approach the lower end of the decision function. Since we are in the negative domain, market participants are risk averse. Protection-buyers will be eager to avoid the (low) risk of the credit event and would like to enter into the contract. The seller has the choice to lose the quarterly payments with probability $P D$ or lose the pre-defined payment in the case of the credit event. If the value of $p$ declines, the discrepancy between the two possible losses goes up. Thus, if $\pi(P D)>P D$, the speculators will not be willing to enter into the contract (this could explain the very limited activity in the market of the sCDS in developed economies at the beginning of crisis). On the other hand, if $\pi(P D)<P D$, the speculators will consider the contract an (almost) risk-free investment, and they may be eager to enter into it. In this situation, we should expect a negative leverage. On the other hand, when the value of $p$ increases, and so does the perceived probability of default, the speculators will remain risk-averse until $P D$ departs from the lower end of the decision function and $p$ reaches a high enough point.

\subsubsection{Case 2: The probability of default is low}

This is the most typical situation in the case of the SCDS of the emerging markets (see Table 2). Let us assume that the value of the spread increases. This may be caused by the growth of the credit event probability or the loss given default. Now, if the 
protection buyer expects future growth of the spread, i.e. $\pi(P D)>P D$, he or she will be eager to enter into the contract. The demand can be boosted by the speculators eager to buy the contract in order to re-sell it in the future. The speculators will increase the demand and cause the more intensive movement of the prices. Thus, we can expect positive leverage.

On the contrary, if market participants perceive the risk and premium as too high, i.e. $\pi(P D)<P D$, the buyers will wait till the trend reverts. The speculators will be eager to sell the contracts rather than buy them. The supply can exceed the demand and the movement of prices will be slow. We should not expect any growth of volatility.

When the spread decreases, we approach the lower end of the decision function. Since we are on the loss side, then as long as $\pi\left(\frac{p}{1-R R}\right)$ is very small, and the discrepancy between $(1-R R) \cdot N$ and $\sum p \cdot N$-very high, the seller will be risk averse. Thus, the protection seller will demand that the value of the spread, $p$, should be high enough to compensate for the risk of the potential default. Consequently, if the spread decreases, and the protection seller perceives the probability of default as higher than the implied from the spread, he will be reluctant to enter into the contract. However, he will enter into the contract if $\pi\left(\frac{p}{1-R R}\right)<\frac{p}{1-R R}$. Also in this case we can expect that the decreasing price could encourage buyers to enter into the contract, so the transaction number can grow and volatility can increase. Here, the leverage parameter will be negative. If, on the contrary, $\pi\left(\frac{p}{1-R R}\right)>\frac{p}{1-R R}$, the protection seller would wait until the spread increases in such a way that its growth will compensate for the increased growth of the default probability (see Eq. 2).

\subsubsection{Case 3: Probability of default is high}

CDS-implied probabilities of default are usually low or moderate. However, as in the case of Greece, they can increase drastically in extreme situations. Under such circumstances, as we are still on the loss side, the market participants become riskseeking. Thus, especially with respect to growth of spreads, speculators will become active and increase the demand, despite the fact that the probability of default they perceive is smaller than 1 . When we consider the protection buyer, we observe that he either loses $N(1-R R)$ with high probability PD or loses $\sum p \cdot N$ with certainty. Because of that, he will be willing to enter into the contract only when he feels that PD is higher than the market says. And so, in the case of sCDS with very high spreads, we can expect a positive leverage. If the spread declines, and the market participants consider probability of default to be higher, the risk-seeking protection buyers can postpone transactions, while the speculators can consider the premium too low to compensate for the high risk of default. Thus, in this case we should not expect any growth of volatility.

\subsubsection{Summary}

To sum up, we postulate that as far as the countries with very small probabilities of default are concerned, we should expect only a negative correlation between spread 
changes and volatility. In the case of the economies exhibiting a low probability of default, the negative correlation should be observed when the probability of default is underweighted, while positive, when it is over-weighted Eventually, with extremely high probabilities of default, the observed correlation should be positive. In the next step of our research, we will try to verify our hypotheses using a volatility model with the leverage effect.

\section{Volatility models with the leverage effect}

The so-called "leverage" phenomenon can be visualised through various GARCHtype models (Bollerslev 1986), e.g. the EGARCH (Nelson 1991), the GJR-GARCH (Glosten et al. 1993), or the APARCH (Ding et al. 1993) one. In these models, their authors introduced an additional parameter to the volatility equation that translates the effect of falling prices into volatility dynamics. The specification is flexible enough to model a positive, negative or no leverage.

In our study, we decided to use stochastic volatility models (SV), which are more flexible than the GARCH ones, and we estimated them using the Bayesian methodology. There were two reasons for doing so: first, the modelled period was hectic (the financial crisis), and secondly — we modelled returns of the series instead of the logarithmic returns. In this case, the interpretation of the resulting data is straightforward (daily changes of the spread), but the properties are not the same as in the case of the log-returns used in stock data models. Therefore, we needed a tool that is flexible enough to capture the dynamics of the series.

\subsection{Stochastic volatility model with the leverage effect}

SV models are usually specified in terms of stochastic differential equations (Yu 2005):

$$
\left\{\begin{array}{l}
d s_{t}=\sigma_{t} d B_{1, t}, \\
d \ln \sigma_{t}^{2}=\alpha+\beta \ln \sigma_{t}^{2} d t+\sigma_{v} d B_{2, t},
\end{array}\right.
$$

where $B_{1, t}$ and $B_{2, t}$ are two Brownian motions. In order to make sure that the conditional variance is positive, the logarithm of $\sigma_{t}^{2}$ is modelled. This is the basic SV model, as proposed by Melino and Turnbull (1990) and Taylor (1994). In order to enable estimation, the model is discretized. For instance, the Euler-Maruyama approximation produces the following result:

$$
\begin{aligned}
& X_{t}=\sigma_{t} u_{t} \\
& \ln \sigma_{t+1}^{2}=\alpha+\phi \ln \sigma_{t}^{2}+\sigma_{v} v_{t+1}
\end{aligned}
$$

where: $X_{t}=s_{t+1}-s_{t}, u_{t}=B_{1, t+1}-B_{1, t}, v_{t}=B_{2, t+1}-B_{2, t}, \phi=1+\beta$.

This formulation of the model is somewhat similar to the $\operatorname{GARCH}(1,1)$ proposition. Contrary to the GARCH model, there are two sources of randomness here: $u_{t}$ and $v_{t}$. The first disturbance describes the randomness connected with the content of new information inflow, while the second-with its intensity. Therefore, the models are 
more flexible than the GARCH ones and can shape volatility of a hectic time series more appropriately.

Similarly to GARCH-type models, SV models can also incorporate asymmetry. Yu (2005) proposed to model it through correlation between $E\left[\ln \sigma_{t+1} \mid X_{t}\right]$ and $X_{t}$ :

$$
\operatorname{corr}\left(B_{1, t}, B_{2, t}\right)=\rho .
$$

When $\rho<0$, we have the (negative) leverage effect. In the discretized form: $u_{t}$ and $v_{t}$ are iid $N(0,1)$ and $\operatorname{corr}\left(u_{t}, v_{t+1}\right)=\rho$.

It can be derived (see: Yu 2005) that:

$$
E\left[\ln \sigma_{t+1} \mid X_{t}\right]=\alpha+\frac{\alpha \phi}{1-\phi^{2}}+\rho \sigma_{v} \exp \left(-\frac{\sigma_{v}^{4}}{4\left(1-\phi^{2}\right)^{2}}+\frac{\sigma_{v}^{2} \alpha}{\left(1-\phi^{2}\right)(1-\phi)}\right) X_{t}
$$

Thus, a fall in the return leads to an increase of $E\left[\ln \sigma_{t+1} \mid X_{t}\right]$-ceteris paribus-and the leverage effect is ensured.

This model is consistent with the one proposed by Shephard (1996). Harvey and Shephard (1996) estimated the model by QML, while Yu (2005) used the Bayesian approach in WinBUGS ${ }^{3}$ software. The advantage of the Bayesian approach over the maximization of the likelihood function is that we avoid a problem of algorithm stacking in local extreme. In order to estimate the model in WinBUGS, it needs to be rewritten to the state-space representation. We followed the approach of Yu (2005) and wrote it in the following way:

$$
\begin{aligned}
& h_{t+1} \mid h_{t}, \alpha, \phi, \sigma_{v}^{2} \sim N\left(\alpha+\phi h_{t}, \sigma_{v}^{2}\right), \\
& X_{t} \mid h_{t+1}, h_{t}, \alpha, \phi, \sigma_{v}^{2}, \rho \sim N\left(\frac { \rho } { \sigma _ { v } } \operatorname { e x p } ( \frac { h _ { t } } { 2 } ) \cdot \left(h_{t+1}\right.\right. \\
& \left.\left.\quad \alpha-\phi h_{t}\right), \exp \left(h_{t}\right) \cdot\left(1-\rho^{2}\right)\right),
\end{aligned}
$$

where $h_{t}=\ln \left(\sigma_{t}^{2}\right)$. The parameter $\rho$ was assumed to be uniformly distributed over the $(-1,1)$ interval. All other priors were specified as in (Yu 2005)-i.e. this is the same specification as in Kim et al. (1998). This representation allows for straightforward estimation using WinBUGS. We chose a 5000-iterations burn-in period and a 20,000iterations follow-up period. All the models were well estimated based on the obtained values of the MCMC error, as well as autocorrelation of the samples.

The model was estimated in two steps. First, we fit the model of conditional mean to the returns of sCDS in order to explain all linear dependencies in the data. Next, for the standardized residuals, we estimated the SV model.

\footnotetext{
3 The BUGS (Bayesian inference Using Gibbs Sampling) project is concerned with flexible software for the Bayesian analysis of complex models using Markov Chain Monte Carlo methods (in short: MCMC). WinBUGS and OpenBUGS are software provided by MRC Biostatic Unit, Cambridge: http://www.mrc-bsu. cam.ac.uk/software/bugs/
} 


\section{Data}

We take into account the 5-year daily sCDS spreads of selected European economies during the years of 2008-2013, traded in euro. Our sample comprises both emerging and developed countries. The countries were chosen based on the availability of data. We present the descriptive statistics of the SCDS returns (changes) in Table 2. (D) denotes developed economies according to the IMF classification up to November 2013 (International Monetary Fund World Economic Outlook 2013). The data are sorted according to their standard deviations. Greece seems to be the most volatile, although we took into account a long period during which there were no transactions of the Greek CDS and their price remained stable. In the last column we present the average probabilities of default computed under the assumption of $40 \%$ recovery rate (see Eq. 2).

In Figs. 1, 2, 3 4, 5 and 6, we present the evolution of spreads. We divided the countries into groups, depending on the similarity of spreads dynamics. And thus, the Baltic states and Iceland are presented in Fig. 1. We observe that the reaction of the spreads to the beginning of the crisis was strong, but the situation stabilized already in 2010. The spreads of Turkey and Russia almost overlap (Fig. 2), especially in the period 2009-2013. The spread of Romanian CDS reacted stronger to Greek problems. The spread of Ukrainian SCDS was similar in dynamics, but took much higher values (Fig. 2). In the case of Visegrád Group and Bulgaria (Fig. 3), we observe that the reaction to the beginning of the crisis was stronger than to the 2010/2011 crisis in all countries but Hungary. However, Hungary experienced its own problems at the same time. In Fig. 4 we placed Italy, Spain and Slovenia. Surprisingly, the

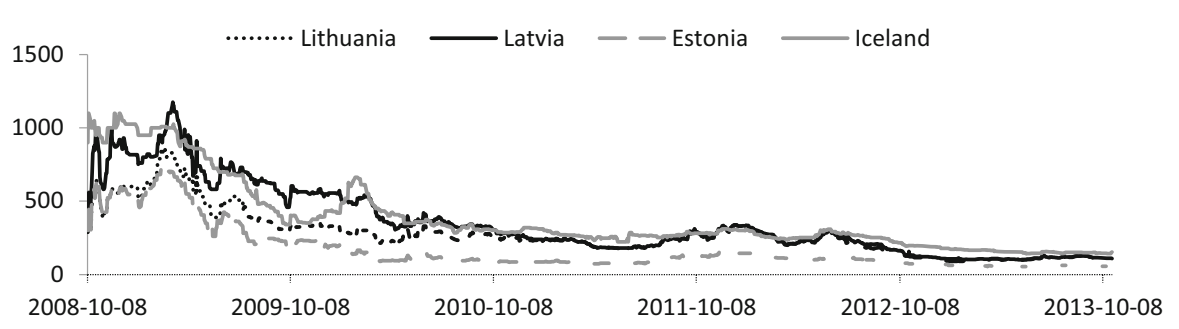

Fig. 1 The evolution of the sCDS spread of the Baltic states (Lithuania, Latvia and Estonia) and Iceland over the period 2008-2013

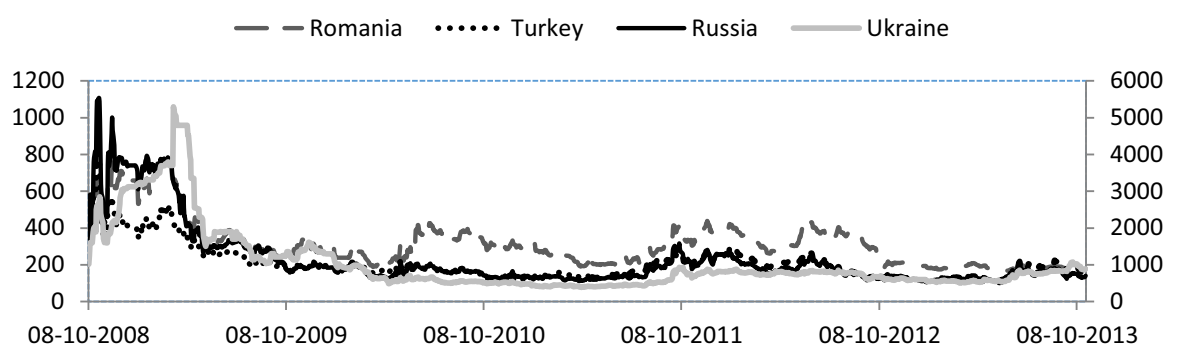

Fig. 2 The evolution of the sCDS spread of Bulgaria, Romania, Russia (left axis) and Ukraine (right axis) over the period 2008-2013 


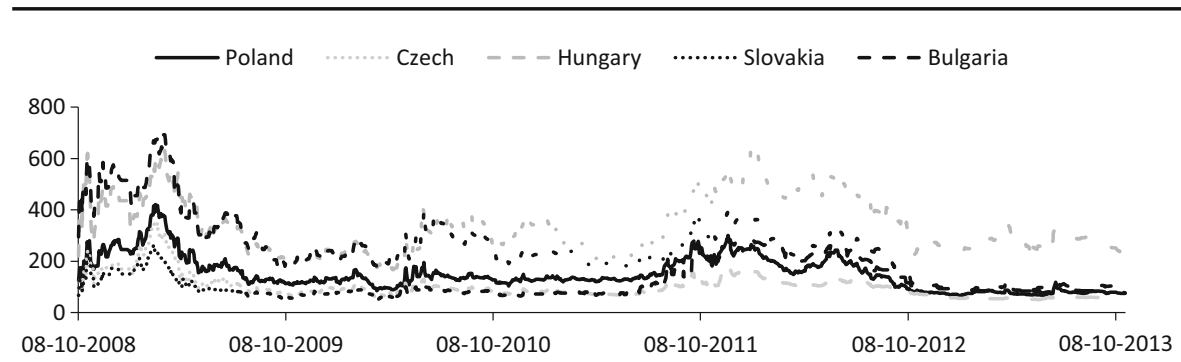

Fig. 3 The evolution of the sCDS spreads of Visegrád Group economies (the Czech Republic, Hungary, Poland, Slovakia) and Bulgaria over the period 2008-2013

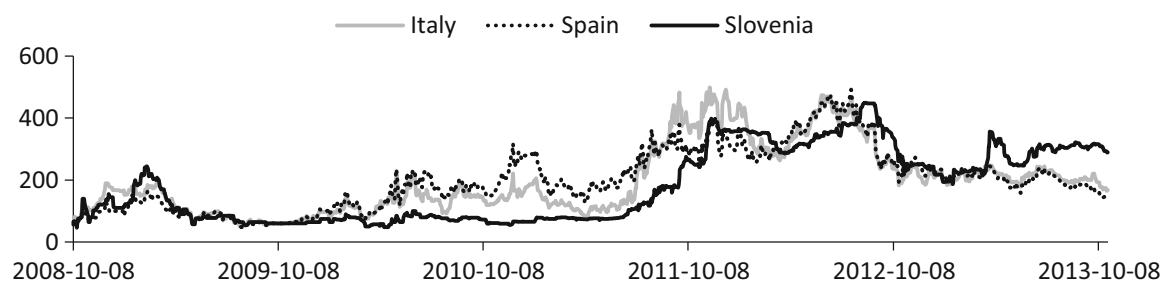

Fig. 4 The evolution of the sCDS spread of Italy, Spain and Slovenia over the period 2008-2013

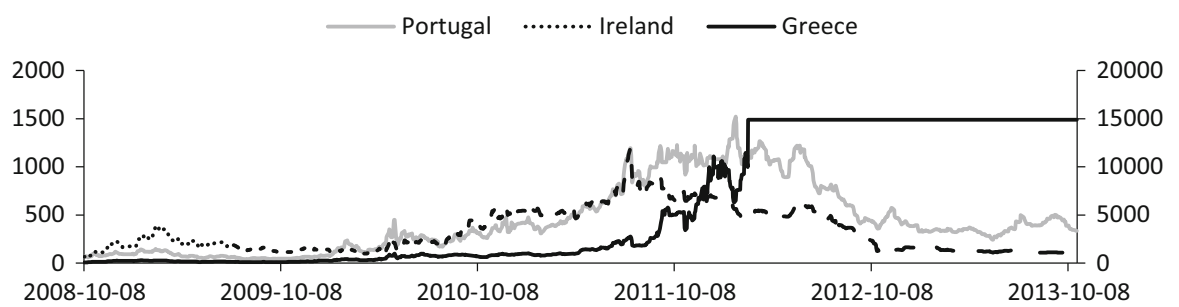

Fig. 5 The evolution of the sCDS spread of Portugal, Ireland and Greece (right axis) over the period 2008-2013

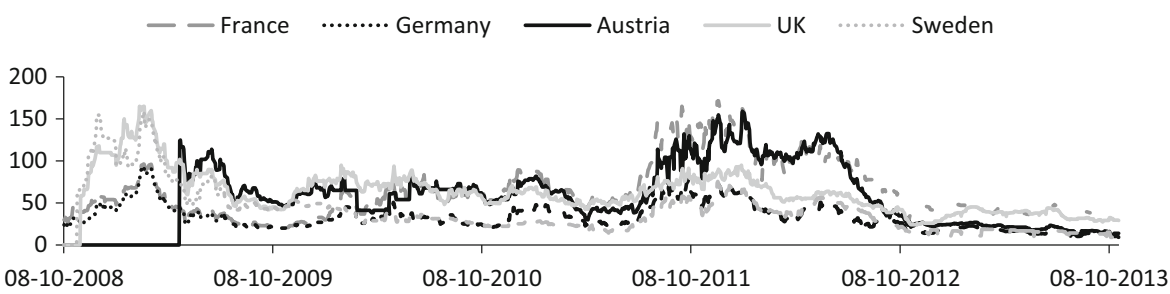

Fig. 6 The evolution of the sCDS spread of developed economies (France, Germany, UK, Austria, and Sweden) over the period 2008-2013

behaviour of the Slovenian CDS spread was more similar to the behaviour of the Mediterranean countries than to the central-European ones. We placed Portugal and Greece together with Ireland in Fig. 5. Ireland and Greece also confronted their own problems, although the spread of Ireland was 10 times lower than the Greek one and the situation stabilized in 2012. However, in the case of Greece, the transactions ceased 
and the spread remained constant. Eventually, France, Germany, Austria, Sweden and the UK are presented in Fig. 6. Yet, we observe that the reaction of France and Austria to the Greek problems was much more spectacular than the German one or the British one.

\section{The leverage effect: the study}

\subsection{The results}

In Fig. 7 and in Table 3 we present the estimates of the leverage effect. We demonstrate the mean and the $95 \%$ confidence interval. When the lower and upper interval values are greater than zero, we conclude that the parameter was positive. When both values are negative-we conclude that the parameter was negative. In all the other cases, we assume that it is insignificant.

The obtained results support our hypotheses. Let us first distinguish the cases of very low and low $p$. In the group of very low premium we have safe, developed economies: Germany, France, Austria, Sweden, UK (Fig. 6; Table 2). The maximum value of $p$ in this group of countries amounted to $160 \mathrm{bp}$ in the analysed period. In all other cases, such value was the minimum one. To the low-spread group we can classify also the Czech Republic and Slovakia. Indeed, in the case of UK, Germany, Sweden, Austria, and the Czech Republic we obtained the negative leverage parameter. In all other cases, the leverage parameter was zero. According to our model, the negative leverage can be present in the SCDS of very low probability of default if the market participants feel that this probability is, in fact, lower than the one implied by the spread. In the last column of Table 3 we present the estimates of the slope parameter $\left(b_{1}\right)$ of the trend equation that was fit to the spreads. In the case of the negative-leveraged sCDS, the trend was declining. This fact can support our thesis that the investors perceived the probability of default as lower than the actual one, if we assume that the movements of prices reflect the expectations of market participants.

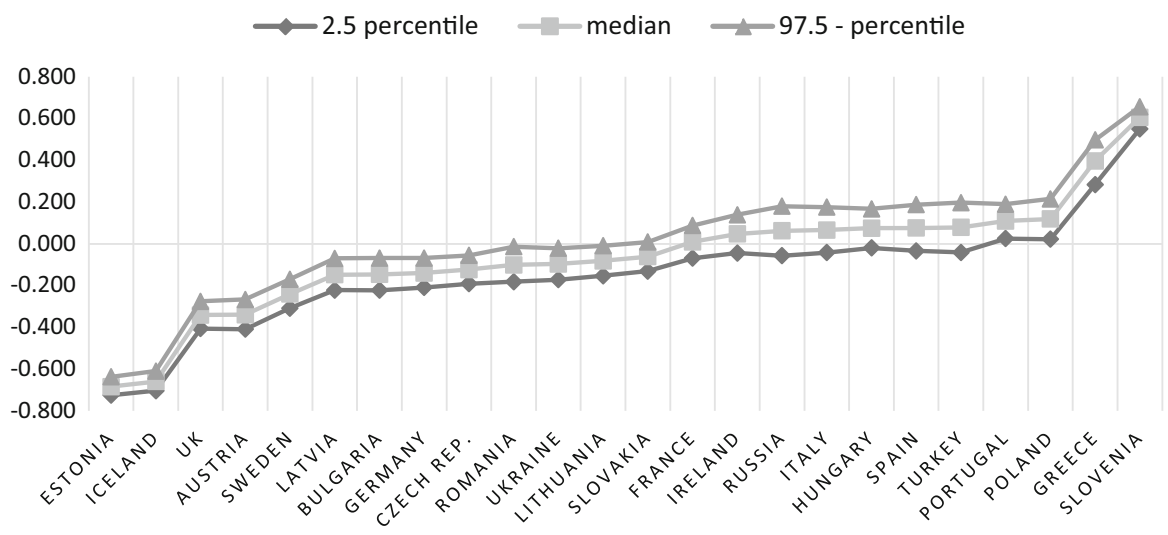

Fig. $795 \%$-confidence interval of the leverage effect parameter 
Table 3 The "leverage effect" in the European markets: the characteristics of distribution and resulting sign of the parameter

\begin{tabular}{|c|c|c|c|c|c|c|c|c|}
\hline Country & $\begin{array}{l}\text { rho } \\
\text { (mean) }\end{array}$ & $\mathrm{SD}$ & $\begin{array}{l}\text { MCMC } \\
\text { error }\end{array}$ & $2.50 \%$ & Median & $97.50 \%$ & $\begin{array}{l}\text { Leverage } \\
\text { sign }\end{array}$ & $b_{1}$ \\
\hline Estonia & -0.683 & 0.022 & 0.000 & -0.725 & -0.684 & -0.637 & - & -0.304 \\
\hline Iceland & -0.6586 & 0.0239 & 0.0005 & -0.7031 & -0.6593 & -0.6095 & - & -0.544 \\
\hline UK & -0.3415 & 0.0333 & 0.0004 & -0.4058 & -0.3413 & -0.2756 & - & -0.046 \\
\hline Austria & -0.3388 & 0.0365 & 0.0006 & -0.4089 & -0.3393 & -0.2665 & - & -0.032 \\
\hline Sweden & -0.2398 & 0.0354 & 0.0004 & -0.3083 & -0.2400 & -0.1694 & - & -0.049 \\
\hline Latvia & -0.147 & 0.039 & 0.001 & -0.222 & -0.148 & -0.069 & - & -0.554 \\
\hline Bulgaria & -0.146 & 0.039 & 0.001 & -0.222 & -0.146 & -0.068 & - & -0.232 \\
\hline Germany & -0.1394 & 0.0356 & 0.0005 & -0.2088 & -0.1398 & -0.0683 & - & -0.015 \\
\hline Czech Republic & -0.123 & 0.035 & 0.000 & -0.191 & -0.123 & -0.055 & - & -0.065 \\
\hline Romania & -0.100 & 0.043 & 0.001 & -0.182 & -0.101 & -0.014 & - & -0.204 \\
\hline Ukraine & -0.096 & 0.038 & 0.001 & -0.172 & -0.097 & -0.021 & - & -1.373 \\
\hline Lithuania & -0.081 & 0.037 & 0.000 & -0.153 & -0.081 & -0.009 & - & -0.335 \\
\hline Slovakia & -0.061 & 0.036 & 0.000 & -0.130 & -0.061 & 0.009 & 0 & 0.023 \\
\hline France & 0.010 & 0.040 & 0.000 & -0.069 & 0.010 & 0.088 & 0 & 0.016 \\
\hline Ireland & 0.048 & 0.047 & 0.001 & -0.044 & 0.048 & 0.139 & 0 & 0.076 \\
\hline Russia & 0.062 & 0.061 & 0.002 & -0.057 & 0.063 & 0.180 & 0 & -0.276 \\
\hline Italy & 0.066 & 0.055 & 0.001 & -0.042 & 0.066 & 0.176 & 0 & 0.166 \\
\hline Hungary & 0.075 & 0.048 & 0.001 & -0.019 & 0.075 & 0.168 & 0 & Insignificant \\
\hline Spain & 0.075 & 0.057 & 0.001 & -0.034 & 0.076 & 0.188 & 0 & 0.165 \\
\hline Turkey & 0.079 & 0.061 & 0.002 & -0.041 & 0.079 & 0.197 & 0 & -0.146 \\
\hline Portugal & 0.1082 & 0.0424 & 0.0007 & 0.0256 & 0.1092 & 0.1901 & + & 0.507 \\
\hline Poland & 0.119 & 0.049 & 0.001 & 0.022 & 0.119 & 0.215 & + & -0.083 \\
\hline Greece & 0.3955 & 0.0544 & 0.0017 & 0.2837 & 0.3971 & 0.4980 & + & 15.541 \\
\hline Slovenia & 0.606 & 0.027 & 0.001 & 0.551 & 0.606 & 0.657 & + & 0.228 \\
\hline
\end{tabular}

$b_{1}$ denotes the coefficient of the trend equation: $y=b_{0}+b_{1} t$

In the case of low-spread countries, the positive value of the leverage was obtained in Portugal, Poland and Slovenia. The assumption that the perceived probability of default was higher than the one implied by the spread can be easily justified in the case of Slovenia. If we take a look at Fig. 4, we can see that the changes of the spread of Slovenian sCDS featured almost the same patterns as the changes of the Spanish and Italian spreads. Although the Slovenian rating was high and stable, investors were unlikely to trust the implied probabilities and they could not have expected that sCDS spread was undervalued. The fact that the premium of the Slovenian sCDS was increasing over the period in question supports this thesis. In the case of Poland, the investors could have been afraid of the spillovers from unstable Hungary, the neighbour economy. If we take a look at Fig. 3, we notice similarities in the evolution of the spreads of Polish and Hungarian sCDS (the Czech Republic, on the contrary, could be associated more with the Slovak Republic, which had already been a member 
of the Eurozone, and the spread of which was lower than the spreads of the remaining V4 economies). The parameter $b_{1}$ estimated for the sCDS trend was negative; however when we look at Fig. 3, we can see that it was definitely reverting. Finally, in the case of Portugal, the trend was upward, the rating was deteriorating, and the investors were likely to expect that Portugal might follow the Greek scenario.

As for the group of low-spread economies, we have seven cases of the negative leverage, namely: Estonia, Iceland, Latvia, Bulgaria, Romania, Ukraine, and Lithuania. In the case of Estonia, Latvia, Lithuania, and Iceland, the spread was downward-sloping in almost the whole period. The foreign-currency rating of Estonia changed from A to BBB in April 2009 and again to A in July 2010. The rating of Iceland at the beginning of the period was equal to BBB; in January 2010 it changed to $\mathrm{BB}$ and improved to BBB in February 2012. In the case of Latvia, the rating was changed to BB from BBB in April 2009 and again to BBB in March 2011. Furthermore, in the case of Lithuania, the foreign currency rating was BBB over the whole period. Since according to the rating, the countries should be considered safe, the speculators most likely perceived the probability of credit event as lower than implied by the spread. The fact that the spread was declining in the whole period supports this thesis as well.

In the negative-leverage group we have also Bulgaria, Romania, and Ukraine. The ratings of Romania and Bulgaria provided by Fitch were BBB in the whole period, while the spreads of Romanian and Bulgarian sCDS were indeed higher than, for instance, the spread of Russian sCDS of the same rating. Moreover, the trends of sCDS were downward-sloping. Thus, the spreads were likely to appear mispriced by the investors.

The rating of Ukraine provided by Fitch did not exceed B-neither in local, nor in a foreign currency. However, the spread was declining in the whole period, resembling the pattern observed in Romania, Turkey and Russia (Fig. 2). Therefore, despite the high values of the spread, the investors could perceive the actual probability of default as lower (the slope coefficient was, indeed, negative). Our sample ends in 2012. Already in 2013, when the situation of Ukraine greatly deteriorated, the market participants did not expect the default. ${ }^{4}$

Finally, we have one case of a very high probability of default-Greece. The average probability of default in the case of Greece amounted to $98 \%$, so we can definitely put it in the "high probability of default" category. The trend was upward sloping, suggesting that the investors most likely perceived the real probability of default as higher than the one implied by the spread. The leverage parameter was positive, confirming our hypothesis.

\section{Summary}

In this article, we discussed the theoretical justification of a leverage parameter in the case of sovereign credit default swaps, referring to investment strategies and the

\footnotetext{
4 Reuters, December 10th, 2013: "The situation is bad and the market knows it. We do not expect a 2014 default in our base case, and neither does the market (...)," Bank of America/Merrill Lynch said in a note (http://www.iol.co.za/business/international/ukraine-cds-surge-to-4-year-high-1.1620142).
} 
behavioural attitude to risk. The leverage was modelled as a correlation coefficient between the return of SCDS and its volatility through the SV model with a leverage coefficient (Yu 2005). We proposed a behavioural explanation of the possible positive and negative correlation between returns and volatility, utilizing the Prospect Theory (Kahneman and Tversky 1979). According to our model, in the case of countries with very low probabilities of default, we should expect only a negative correlation between the spread changes and volatility. In the case of economies with a low probability of default, the negative correlation should be observed when the probability of default is underweighted, and the positive correlation - when it is over-weighted. And finally, in the case of the extremely high probabilities of default, the observed correlation should be positive.

As regards the economies with a very low probability of default, we obtained only negative correlations (UK, Germany, Sweden, Austria, the Czech Republic). In the case of extremely risky Greece, the parameter was positive. Furthermore, in the case of moderate-risk economies the correlations varied. We obtained a positive leverage in the case of Poland, Portugal and Slovenia and we explain this result by claiming that the probabilities of default could have been underpriced in these cases. The spreads of Polish and Slovenian sCDS were growing over the whole period, or over most of it. Thus, if we assume that the market was effective, these tendencies could suggest that the market participants expected that the spreads should be higher. Besides, in each case the market participants might have been afraid of spillovers from the suffering neighbour economies (Hungary in the case of Poland, and Greece in the case of Slovenia and Portugal).

In the case of negative-leveraged economies from the moderate-risk group (the Baltic states, Iceland, Bulgaria, Romania and Ukraine), we observe the decline of the spreads over the period. This could suggest that the market participants expected further decline of the probabilities of default and considered the spreads overpriced. Moreover, in most cases the ratings of specific countries suggested good or stable economic conditions (apart from Ukraine). Thus, the results confirm our thesis.

On the other hand, our analysis is not free of drawbacks. First of all, we assume that the volatility of sCDS is impacted only by own returns of the instruments. This does not have to be the case. Undoubtedly, the dynamics of financial instruments are influenced by the dynamics of other financial instruments. In the case of sCDS, such instruments could be sovereign bonds or the sCDS of neighbouring countries. For instance, Kliber (2014) shows that the correlation between the returns of Polish and Hungarian sCDS was influenced by the Greek problems. The growth of the sCDS premiums at the beginning of the crisis was also a result of the panic in the market. In such a case, the growth of volatility could be correlated with the extreme positive or negative returns in the neighbouring SCDS or the bond market.

Acknowledgments The author would like to thank Jacek Wallusch for inspiration and help with the research presented in the paper, Malgorzata Doman for her support with the theoretical part, Barbara Bedowska-Sojka for her kind advice on volatility behavior, as well as the participants of the seminars of Department of Applied Mathematics (Poznan University of Economics), the participants of FindEcon conference (Forecasting Financial Markets and Economic Decision-Making, 2014, Lodz, Poland) and the participants of the ECEE conference (Economic Challenges in Enlarged Europe, 2014, Tallin, Estonia) for their comments and discussion on the early version of the research. All the remaining errors are mine. 
Open Access This article is distributed under the terms of the Creative Commons Attribution 4.0 International License (http://creativecommons.org/licenses/by/4.0/), which permits unrestricted use, distribution, and reproduction in any medium, provided you give appropriate credit to the original author(s) and the source, provide a link to the Creative Commons license, and indicate if changes were made.

\section{References}

Adam, M. (2013). Spillovers and contagion in the sovereign CDS market. Bank and Credit, 44(6), 571-604. Ang, A., \& Longstaff, F. A. (2013). Systemic sovereign credit risk: Lessons from the US and Europe. Journal of Monetary Economics, 60(5), 493-510.

Arghyrou, M. G., \& Kontonikas, A. (2012). The EMU sovereign-debt crisis: Fundamentals, expectations and contagion. Journal of International Financial Markets, Institutions and Money, 22(4), 658-677.

Augustin, P. (2014). Sovereign credit default swap premia. Journal of Investment Management, 12(2), 65-102.

Aydemir, A. C., Gallmeyer, M., \& Hollifield, B. (2007). Financial leverage and the leverage effect-A market and firm analysis. AFA 2007 meeting paper. https://student-3k.tepper.cmu.edu/gsiadoc/wp/ 2007-E31.pdf. Accessed 23 June, 2015.

Będowska-Sójka, B. (2014). Wpływ informacji na ceny instrumentów finansowych. Analiza danych śróddziennych [Impact of information on the price of financial instruments. Analysis of intraday data]. Poznan: Poznan University of Economics Press.

Black, F. (1976). Studies in stock price volatility changes. In Proceedings of the 1976 meeting of the business and economic statistics section (pp. 177-181), American Statistical Association.

Bollerslev, T. (1986). Generalized autoregressive conditional heteroskedasticity. Journal of Econometrics, 31, 307-327.

Calice, G., Miao, R.-H., Štěrba, F., \& Vašiček, B. (2015). Short-term determinants of idiosyncratic sovereign risk premium: A regime-dependent analysis for European credit default swaps. Journal of Empirical Finance. doi:10.1016/j.jempfin.2015.03.018.

Campbell, J., \& Hentschel, H. (1992). Non news is good news: An asymmetric model of changing volatility in stock returns. Journal of Financial Economics, 31, 281-318.

Caceres, C., Guzzo, V., \& Segoviano, M. (2010). Sovereign spreads: Global risk aversion, contagion or fundamentals? IMF Working Paper 10/120. https://www.imf.org/external/pubs/ft/wp/2010/wp10120. pdf. Accessed 23 June 2015.

Che, Y.-K., \& Sethi, R. (2015). Credit market speculation and the cost of capital. American Economic Journal: Microeconomics, 6(4), 1-34.

Chen, X., \& Ghysels, E. (2011). News—good or bad—and its impact on volatility predictions over multiple horizons. Review of Financial Studies, 24(1), 46-81.

Danielsson, J., Shin, H. S., \& Zigrand, J. P. (2010). Risk Appetite and Endogenous Risk. FMG Discussion Papers dp647, Financial Markets Group. http://ideas.repec.org/p/fmg/fmgdps/dp647.html. Accessed 23 June, 2015.

Ding, Z., Granger, C. W., \& Engle, R. (1993). A long memory property of stock market returns and a new model. Journal of Empirical Finance, 1, 83-106.

ECB. (2009). Credit default swaps and counterparty risk. https://www.ecb.europa.eu/pub/pdf/other/ creditdefaultswapsandcounterpartyrisk2009en.pdf

Figlewski, S., \& Wang, X. (2000). Is the "leverage effect” a leverage effect? Working paper. doi:10.2139/ ssrn.256109.

French, K., Schwert, W., \& Stambaugh, R. (1987). Expected stock returns and volatility. Journal of Financial Economics, 19, 3-29.

Glosten, L. R., Jagannathan, R., \& Runkle, D. E. (1993). On the relation between the expected value and the volatility of the nominal excess return on stocks. Journal of Finance, 48, 1779-1801.

Grady, J., \& Lee, R. J. (2012). Sovereign CDS: Lessons from the Greek debt crisis. Memorandum. Richards Kibbe \& Orbe LPP, 1-4. http://www.rkollp.com/assets/attachments/ Sovereign $\% 20$ CDS $\% 20$-\%20Lessons\%20from\%20the\%20Greek\%20Debt\%20Crisis.pdf. Accessed 03 September, 2015.

Harvey, A. C., \& Shephard, N. (1996). The estimation of an asymmetric stochastic volatility model for asset returns. Journal of Business and Economic Statistics, 14, 429-434. 
Hasanhodzic, J., \& Lo, A. W. (2011). Black's leverage effect is not due to leverage. Working Paper. doi:10. 2139/ssrn.1762363.

Heinz, F. F., \& Sun, Y. (2014). Sovereign CDS spreads in Europe-The role of global risk aversion, economic fundamentals, liquidity and spillovers. International Monetary Fund Working Paper 14/17, https:// www.imf.org/external/pubs/ft/wp/2014/wp1417.pdf. Accessed 23 June, 2015.

Hens, T., \& Steude, S. C. B. (2009). The leverage effect without leverage. Finance Research Letters, 6(2), 83-94.

Hibbert, A. M., Daigler, R. T., \& Dupoyet, B. (2008). A behavioral explanation for the negative asymmetric return-volatility explanation. Journal of Banking and Finance, 32, 2254-2266.

International Monetary Fund World Economic Outlook. (April, 2013). Hopes, realities and risk.

ISDA. (2014). Adverse liquidity effects on the EU uncovered sovereign CDS ban, ISDA Research Note. http://www2.isda.org/functional-areas/research/research-notes/.

Kalev, P. S., Liu, W. M., Pham, P. K., \& Jarnecic, E. (2004). Public information arrival and volatility of intraday stock returns. Journal of Banking and Finance, 28, 1441-1467.

Kahneman, D., \& Tversky, A. (1979). Prospect theory: An analysis of decisions under risk. Econometrica, 47(2), 263-292.

Kahneman, D., \& Tversky, A. (1992). Advances in prospect theory: Cumulative representation of uncertainty. Journal of Risk and Uncertainty, 5(4), 297-323.

Kahneman, D. (2011). Thinking fast and slow. New York: Farrar, Strauss and Giroux.

Kim, S., Shephard, N., \& Chib, S. (1998). Stochastic volatility: Likelihood inference and comparison with ARCH models. Review of Economic Studies, 65, 361-393.

Kliber, A. (2013). Influence of the Greek crisis on the risk perception of European economies. Central European Journal of Economics Modelling and Econometrics, 5(2), 125-161.

Kliber, A. (2014). The dynamics of sovereign credit default swaps and the evolution of the financial crisis in selected central European economies. Czech Journal of Economics and Finance, 64(4), 330-350.

Lamoureux, C. G., \& Lastrapes, W. D. (1990). Heteroskedasticity in stock return data: Volume versus GARCH effects. Journal of Finance, 45, 220-229.

Lesplingart, C., Majois, C., \& Petitjean, M. (2012). Liquidity and CDS premiums on European companies around the subprime crisis. Review of Derivatives Research, 15, 257-281.

Longstaff, F. A., Pan, J., Pendersen, L. H., \& Singleton, K. (2011). How sovereign is sovereign credit risk? American Economic Journal: Macroeconomics, 3(2), 75-103.

Meine, C., Supper, H., \& Weiß, G. N. F. (2015). Do CDS spread move in commonality with liquidity? Review of Derivative Research. doi:10.1007/s11147-015-9110-y.

Melino, A., \& Turnbull, S. (1990). Pricing foreign currency options with stochastic volatility. Journal of Econometrics, 45, 239-265.

Meyer, R., \& Yu, J. (2000). BUGS for a Bayesian analysis of stochastic volatility models. The Econometrics Journal, 3, 198-215.

Nelson, D. B. (1991). Conditional heteroskedasticity in asset returns: A new approach. Econometrica, 59, 347-370.

Olsen, R. A. (1997). Prospect theory as an explanation of risky choice by professional investors: Some evidence. Review of Financial Economics, 6(2), 225-232. doi:10.1016/S1058-3300(97)90008-2.

Pindyck, R. (1984). Risk, inflation, and the stock market. American Economic Review, 74, 335-351.

Shephard, N. (1996). Statistical aspects of ARCH and stochastic volatility. In D. R. Cox, D. V. Hinkley, \& O. E. Barndorff-Nielson (Eds.), Time series models in econometrics, finance and other fields (pp. 1-67). London: Chapman \& Hall.

Saretto, A., \& Tookes, H. E. (2013). Corporate leverage, debt maturity and credit default swaps: The role of credit supply. Review of Financial Studies, 26(5), 1190-1247.

Taylor, S. J. (1994). Modeling stochastic volatility: A review and comparative study. Mathematical Finance, $4(2), 183-204$.

Yu, J. (2005). On leverage in a stochastic volatility model. Journal of Econometrics, 127(2), 165-178.

Zhang, G. (2013). Sovereign credit default swap. In Hung-Gay Fung, Yiuman Tse (Eds.), International Financial Markets (Frontiers of economics and globalization (Vol. 13, pp. 91-107). Emerald Group Publishing Limited. doi:10.1108/S1574-8715(2013)0000013010. http://www.mrc-bsu.cam. ac.uk/software/bugs/. 